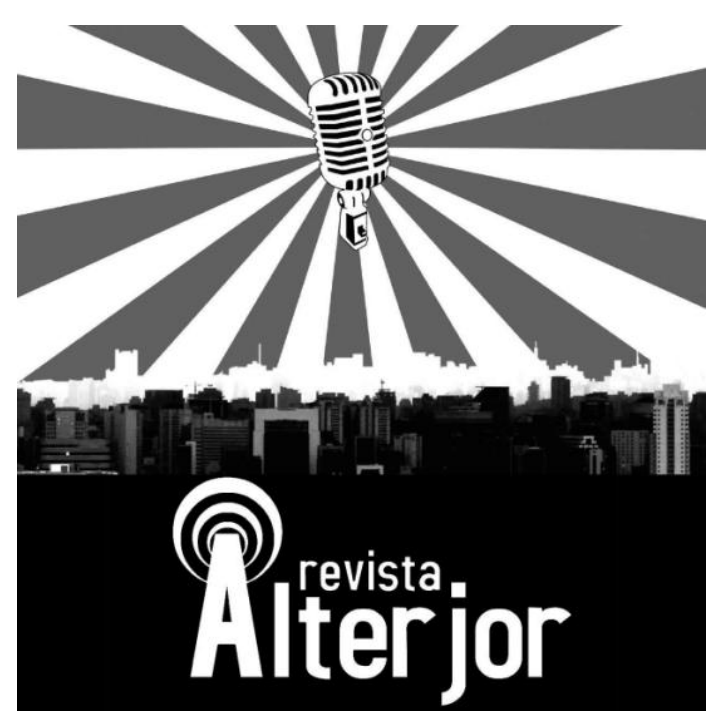

\title{
O JORNALISMO TELEVISIVO NO INTERIOR GAÚCHO: OLHARES PARA O JORNAL DO ALMOÇO E PARA O JORNAL NT SUL
}

\author{
Paulo Marques ${ }^{1}$ \\ Michele Negrini $^{2}$
}

\begin{abstract}
RESUMO: O telejornalismo praticado pelas emissoras de televisão no Rio Grande do Sul vem passando por processos de reestruturação e diminuição dos espaços regionais de notícias. Até mesmo a emissora RBS TV, que ainda atendia de certa forma esta demanda, deixou de produzir consideravelmente conteúdos regionais a partir da pandemia de Covid19. Por outro lado, a TV Cachoeira pode ser considerada um exemplo de produção de jornalismo tipicamente local. O estudo tem por objetivo problematizar a importância do jornalismo regional televisivo do Rio Grande do Sul, analisar a redução da produção regional na RBS TV e refletir sobre a experiência da TV Cachoeira. A análise será aprofundada nos programas "Jornal do Almoço", da RBS TV, e "Jornal NT SUL", da TV Cachoeira, com a observação de cinco edições dos dois noticiários durante uma semana. Como constatações, cabe ressaltar que enquanto a RBS TV está diminuindo o conteúdo para o público do interior, a TV Cachoeira cumpre com o objetivo de levar informação jornalística ao seu telespectador local.
\end{abstract}

PALAVRAS-CHAVE: jornalismo regional. jornalismo televisivo. Jornal do Almoço. Jornal NT SUL.

ABSTRACT: The telejournalism practiced by television stations in Rio Grande do Sul has been going through processes of restructuring and reduction of regional news spaces. Even the broadcaster RBS TV, which still somewhat met this demand, stopped producing considerably regional content from the Covid pandemic19. On the other hand, TV Cachoeira can be considered an example of typically local journalism production. The study aims to discuss the importance of regional television journalism in Rio Grande do Sul, analyze the reduction of regional production on RBS TV and reflect on the experience of TV Cachoeira. The analysis will be deepened in the programs "Jornal do Almoço", on RBS TV, and "Jornal NT SUL", on TV Cachoeira, with the observation of five editions of the two news programs during a week. As findings, it is noteworthy that while RBS TV is reducing content for the public in the interior, TV Cachoeira fulfills the objective of taking journalistic information to its local viewers.

KEYWORDS: regional journalism. television journalism. Jornal do Almoço. Jornal NT SUL.

\footnotetext{
${ }^{1}$ Acadêmico do curso de Jornalismo da Universidade Federal de Pelotas. E-mail: paulomar.rg@ gmail.com

2 Orientadora do trabalho. Professora do curso de Jornalismo da Universidade Federal de Pelotas. Doutora em Comunicação pela PUC RS. E-mail: mmnegrini@yahoo.com.br
}

\section{Revista ALTERJOR}

Grupo de Estudos Alterjor: Jornalismo Popular e Alternativo (ECA-USP)

Ano 12 - Volume 01 - Edição 25 - Janeiro-Junho de 2022

Av. Professor Lúcio Martins Rodrigues, 443, Cidade Universitária, São Paulo, CEP: 05508-020 


\section{Introdução}

O objetivo deste artigo é problematizar a importância do jornalismo para as populações do interior do estado do Rio Grande do Sul, com a observação da produção regional da RBS TV e da TV Cachoeira, aprofundando o estudo nos programas jornalísticos Jornal do Almoço e Jornal NT SUL, através da análise de cinco edições de cada um dos programas.

O jornalismo exerce uma função social muito importante, que é levar informações com credibilidade ao público, dando suporte para que a população possa compreender o seu contexto social. O jornalismo regional se caracteriza por tratar de assuntos relacionados ao cotidiano de uma determinada cidade ou região, em que os fatos objetos da cobertura jornalística tendem a afetar diretamente a vida das pessoas inseridas em uma determinada comunidade. Esporadicamente, de acordo com a importância ou relevância do fato, as notícias regionais podem ser tratadas em uma abrangência estadual ou, ainda, alcançar uma visibilidade em cobertura nacional.

O jornalismo regional constitui-se como uma prática, desenvolvida por cidades de grande e médio porte, que pode extrapolar os limites territoriais da sede dos seus veículos e atender noticiosamente centros urbanos menores que não dispõem de meios de comunicação tradicionais ou outros canais de informação para se informar acerca do próprio cotidiano ou para realizar suas solicitações. (REIS, 2018, p. 65)

A importância deste tipo de jornalismo se dá pelo fato de que muitos dos temas abordados no cotidiano de um determinado público local não teriam destaque fora do âmbito demográfico dos quais pertencem, não fosse essa cobertura regionalizada. Além disso, quanto mais regionalizada for a cobertura jornalística, mais efetividade ela terá na fiscalização e na cobrança de ações junto ao poder público desta parcela da população. Em relação à importância do jornalismo regional, Assis e Rangel (2006, p.2) assinalam:

O jornalismo regional é de grande importância, pois cria vínculos com as pessoas e fortificam a identidade do lugar. Além de ser importante meio de informação para as pessoas do local, pois estas preferem ver notícias da sua cidade ou região a ver notícias que não lhe causam muito impacto. A criação de um jornal regional fomenta a participação dos indivíduos, e a interação e formação social do grupo.

\section{Revista ALTERJOR}

Grupo de Estudos Alterjor: Jornalismo Popular e Alternativo (ECA-USP)

Ano 12 - Volume 01 - Edição 25 - Janeiro-Junho de 2022 


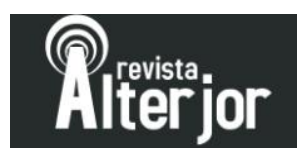

Assis e Rangel (2006) ainda destacam que o jornalismo regional consegue fomentar a participação das pessoas em âmbito social e gerar interação e formação social dos grupos. As autoras ainda apontam que o jornalismo regional também é importante por proporcionar o agrupamento das pessoas da região e, também, e por gerar às pessoas a noção de pertencimento a um grupo. $\mathrm{O}$ pensamento das autoras remete à identificação gerada na tessitura de um telejornal com âmbito local, que leva ao público notícias de seus entornos.

Para Ribeiro (2005), o jornalismo regional informa o que mais de perto interessa ao seu público, pois convive próximo aos problemas da comunidade. Por estar perto do cidadão e tratar de temas diretamente relacionados à sua população, acaba tornando-se um facilitador para o exercício da cidadania, para o desenvolvimento local e para a fiscalização dos seus direitos políticos e administrativos.

Ainda na perspectiva de discorrer sobre o jornalismo regional na televisão, cabe convocar o pensamento de Puhl (2014, p.3), que fala que neste tipo de jornalismo há mais facilidade em visualização da proximidade do repórter com a comunidade.

No telejornalismo regional, conseguimos visualizar com mais facilidade essa proximidade do repórter com o local de forma mais natural, pois muitas vezes é a mesma equipe que faz a cobertura dos assuntos importantes dessa comunidade, o que acaba levando-a a se envolver emocionalmente com as fontes. Em outras palavras, em veículos cuja pauta está mais concentrada na comunidade, de uma forma ou outra as fontes acabam sendo repetidas e se tornando conhecidas dos repórteres, assim como a equipe de reportagem, ao dar voz ao cidadão, recebe legitimidade por parte dele quando este vê na televisão suas reclamações e sua imagem.

No olhar de Pinna (2020), a importância do jornalismo local e do regional se dá justamente no fato de podermos visualizar programas produzidos nas regiões e voltados para a cobertura jornalísticas de diversos municípios e não somente das cidades-sede da TV que gera as notícias, o que ocasiona uma ampliação da área de cobertura das emissoras.

Também falando sobre jornalismo regional, Fernandes (2012) enfoca como sendo importante que o universo televisivo estabeleça uma relação com o público. A

\section{Revista ALTERJOR}

Grupo de Estudos Alterjor: Jornalismo Popular e Alternativo (ECA-USP)

Ano 12 - Volume 01 - Edição 25 - Janeiro-Junho de 2022 Av. Professor Lúcio Martins Rodrigues, 443, Cidade Universitária, São Paulo, CEP: 05508-020 


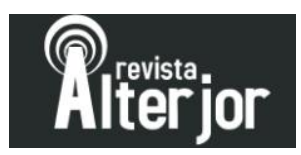

autora destaca que o telejornalismo regional pode se mostrar como uma forma de geração destes vínculos.

No universo televisivo, é possível observar a necessidade de estabelecer uma identidade com o público. E a regionalização é um caminho para isso, uma vez que mesmo tendo notícia em nível global, as pessoas necessitam de informações que estão próximas da sua realidade, ou seja, elas precisam ter notícias sobre o que está acontecendo no ambiente em que vivem, no bairro em que moram. (FERNANDES, 2012, p.18)

Como disse Fernandes (2012), as pessoas carecem de saber assuntos de suas proximidades, de seus arredores, por isso, a proximidade com o espectador se mostra como um fator primordial de seleção de notícias quando falamos em telejornalismo regional. Alguns fatores são determinantes para que os acontecimentos se transformem em notícias, como por exemplo, a notoriedade da pessoa envolvida, a relevância do assunto, a novidade, o inesperado, a controvérsia, o escândalo, a proximidade do acontecimento, entre outros. Estas características de um acontecimento são definidas no jornalismo como critérios de noticiabilidade ou valor-notícia. Wolf (2003) entende que valores-notícia são critérios de relevância que se constituem ao longo do processo de seleção e de construção da notícia. Para Traquina (2008, p. 80), "um valor-notícia fundamental da cultura jornalística é a proximidade, sobretudo em termos geográficos, mas também em termos culturais". Desta forma, um dos critérios de seleção de notícias mais determinantes para a produção jornalística em nível regional é o da proximidade. Mesmo que um fato seja de bastante importância em nível nacional, por exemplo, se ele não tiver relação com alguma realidade local, poderá ser descartado do noticiário regional. Uma pessoa que mora em determinada cidade do interior e distante da capital, geralmente se interessa mais pelo que acontece nas ruas da sua cidade do que o congestionamento do trânsito nas avenidas da metrópole do seu estado ou do país que comumente aparecem nos noticiários estaduais e nacionais. Da mesma forma, os assuntos políticos que envolvem a prefeitura da cidade podem impactar mais diretamente na vida da população do que um projeto de lei que tramita na assembleia legislativa do estado ou na câmara legislativa federal.

Revista ALTERJOR

Grupo de Estudos Alterjor: Jornalismo Popular e Alternativo (ECA-USP)

Ano 12 - Volume 01 - Edição 25 - Janeiro-Junho de 2022

Av. Professor Lúcio Martins Rodrigues, 443, Cidade Universitária, São Paulo, CEP: 05508-020 


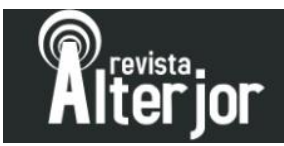

\section{A TV brasileira no contexto do interior}

De acordo com Ferraz (2005), após a chegada da televisão no Brasil, no ano de 1950, e a criação da TV Tupi, a primeira emissora de televisão que se instalou em uma cidade do interior do Brasil foi a TV Bauru. A concessão foi obtida no ano de 1959 e a fundação da emissora ocorreu em 1960. Até este acontecimento, as emissoras de televisão no Brasil só existiam em capitais. Na época, a cidade de Bauru possuía 53 mil habitantes e a programação da emissora era constituída de três horas diárias. A partir de 1965, as Organizações Globo passaram a comandar a TV Bauru e a TV Paulista, que viria a se tornar a TV Globo São Paulo.

No Rio Grande do Sul, Finger (2009) aponta que a TV tem uma produção regional inferior ao que pode ser esperado. "O atual sistema de redes nacionais sufocou a programação local que tem dificuldades de se firmar, tanto em índices de audiência, quanto em sustentabilidade econômica" (FINGER, 2009, s/p). A autora demarca pontos importantes da TV em âmbito local no estado destacando que a primeira emissora de Televisão no RS foi a TV Piratini, que entrou no ar em 1959; já a segunda foi a TV Gaúcha, com inauguração em 29 de setembro de 1962; a terceira foi a TV Difusora, que foi ao ar em 10 de outubro de 1969 e foi a TV pioneira na transmissão em cores no país, mostrando a inauguração da festa da uva, em Caxias do Sul, em 1972. A autora destaca também que na década de 70 foi ao ar a TV Educativa, fazendo conteúdo voltado à educação e à cultura. Finger fala ainda que em 1979 a empresa Caldas Júnior inaugurou a TV Guaíba e que em 1980 foi ao ar a TV Pampa. “A última tentativa de uma televisão verdadeiramente local surgiu em 1980 com a inauguração da TV Pampa, pertencente à Rede Pampa de Comunicação do empresário gaúcho Otávio Gadret, que, até então, atuava na área de rádio" (FINGER, 2009, s/p). Ela analisa a produção local no Estado do Rio Grande do Sul contexto do ano de 2009:

No cenário gaúcho atual, a produção local das televisões investe, preferivelmente, em jornalismo. Os espaços, geralmente restritos, observam a lógica de uma programação que é igual em todo o país. Assim, as emissoras adotam programas que vão ao ar junto aos jornalísticos nacionais e também se estendem, ao logo do dia, em horários mais ou menos previsíveis. Uma edição no início da manhã, outra próxima ao horário do almoço e por fim, um telejornal de pequena

Revista ALTERJOR

Grupo de Estudos Alterjor: Jornalismo Popular e Alternativo (ECA-USP)

Ano 12 - Volume 01 - Edição 25 - Janeiro-Junho de 2022 Av. Professor Lúcio Martins Rodrigues, 443, Cidade Universitária, São Paulo, CEP: 05508-020 
duração, dentro do chamado prime time, horário nobre em termos de share (participação nos aparelhos ligados). (FINGER, 2009, s/p)

Todas estas experiências locais de telejornalismo estavam relacionadas com a capital e região metropolitana de Porto Alegre, sendo que a primeira experiência em levar emissoras para o interior do estado foi através do grupo RBS de comunicação. A origem da RBS TV se deu em 29 de dezembro de 1962, com a fundação da TV Gaúcha, canal 12, em Porto Alegre. Inicialmente afiliada à extinta TV Excelsior, passou a integrar a Rede Globo em 1967. Dois anos depois, em 1969, entraram no ar as primeiras emissoras no interior do estado, a TV Imembuí, em Santa Maria, e a TV Caxias, em Caxias do Sul. No ano de 1972, eram criadas outras emissoras no interior do estado, como a TV Tuiuti, em Pelotas, e a TV Erechim. A seguir, foram criadas outras emissoras no interior do estado, como em Uruguaiana (1974), Bagé e Rio Grande (1977) e Cruz Alta (1979). A denominação RBS TV (Rede Brasil Sul de Televisão) passou a ser utilizada a partir de 1979. Após, foram ainda criadas as emissoras de Passo Fundo (1980), Santa Cruz do Sul (1988) e Santa Rosa (1992). Segundo dados de 2015 da emissora, a sua cobertura de sinal atinge $98,8 \%$ do estado do Rio Grande do Sul e a totalidade dos 497 municípios gaúchos, alcançando 11,1 milhões de telespectadores ${ }^{3}$.

Uma das principais características do grupo RBS é a sua regionalização, com destaque para abrangência dos seus veículos em todo o estado do Rio Grande do Sul. Daí, inclusive, vem a origem do seu nome. Até 2016, o grupo RBS estendia a sua atuação ao estado vizinho de Santa Catarina, com jornais impressos, emissoras de rádio e televisão espalhadas pela capital e em várias cidades do interior catarinense. Com o aprofundamento de uma crise financeira, a empresa acabou vendendo a propriedade para o grupo de comunicação Notícias de Santa Catarina (NSC). Desde então, a RBS passou a focar exclusivamente no Rio Grande do Sul.

Entre as emissoras de televisão em canal aberto com sinal abrangendo o estado do Rio Grande do Sul, a RBS TV é a única que ainda possui telejornais com apresentação de notícias a partir de cidades do interior do estado e para um público

\footnotetext{
${ }^{3}$ Disponível em: <http://redeglobo.globo.com/rs/rbstvrs/noticia/2011/12/historia.html>. Acesso em 25 abr. 2021.
}

Revista ALTERJOR

Grupo de Estudos Alterjor: Jornalismo Popular e Alternativo (ECA-USP)

Ano 12 - Volume 01 - Edição 25 - Janeiro-Junho de 2022

Av. Professor Lúcio Martins Rodrigues, 443, Cidade Universitária, São Paulo, CEP: 05508-020 


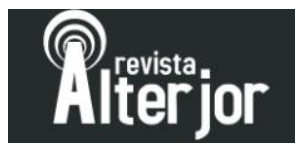

definido na sua região de abrangência demográfica. Outra emissora que possuía descentralização estadual era a TV Pampa, que atualmente retransmite o sinal da RedeTV!. No entanto, durante a última década ela já havia encerrado as produções da TV Pampa Sul e, em agosto de 2020, encerrou definitivamente as produções das outras emissoras ainda existentes (TV Pampa Norte e TV Pampa Centro) ${ }^{4}$. A partir de então, juntamente com Record, SBT e Band, não possui produção de programas jornalísticos no interior do estado 5 .

Atualmente, de acordo com a programação disponível nos sites das emissoras, os telejornais estaduais apresentados são os seguintes: RBS TV (Bom dia Rio Grande, Jornal do Almoço, RBS Notícias), RedeTV! (“Jornal da Pampa", "Atualidades Pampa" - debates), Record ("Rio Grande no Ar", "Balanço Geral RS”, "Cidade Alerta RS”, "Rio Grande Record”), SBT (“SBT Rio Grande 1ª edição”, "SBT Rio Grande 2a edição”), Band ("RS Urgente", "Band Cidade") 6 . Atualmente, estes telejornais possuem um conteúdo único veiculado para todo o estado do Rio Grande do Sul.

Além destas emissoras que possuem abrangência estadual em canal aberto, existe na cidade de Cachoeira do Sul a TV Cachoeira, uma emissora local que retransmite o sinal nacional da TV Novo Tempo. Ela possui um programa jornalístico diário chamado "Jornal NT Sul”, que vai ao ar de segunda à sexta-feira no horário do meio dia e possui ênfase para os fatos da cidade de Cachoeira do Sul, com reportagens, entrevistas e produção de conteúdo jornalístico local, além de algumas matérias em nível estadual ou nacional.

Mesmo com o avanço de outras tecnologias digitais, a televisão ainda mantém um protagonismo, em função da sua ampla abrangência de público e da capacidade de envolvimento com o meio social. De acordo com Bourdieu (1997, p. 23) "a televisão tem uma espécie de monopólio de fato sobre a formação das cabeças de uma parcela muito importante da população". Além disso, a televisão é uma mídia de fácil acesso e

\footnotetext{
4 Disponível em: <https://coletiva.net/pelo-rs/rede-pampa-encerra-operacoes-de-jornalismo-no-interiorgaucho,366037.jhtml>. Acesso em: 25 abr. 2021.

${ }^{5}$ Disponível em: <https://twitter.com/televisaonors/status/1291446945396011008>. Acesso em: 25 abr. 2021.

${ }^{6}$ Programação retirada do Jornal Zero Hora, pág. 4 do Segundo Caderno, 08 de abril de 2021.
}

Revista ALTERJOR

Grupo de Estudos Alterjor: Jornalismo Popular e Alternativo (ECA-USP)

Ano 12 - Volume 01 - Edição 25 - Janeiro-Junho de 2022

Av. Professor Lúcio Martins Rodrigues, 443, Cidade Universitária, São Paulo, CEP: 05508-020 


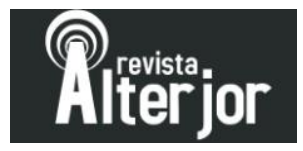

abrange o universo de público, incluindo as pessoas mais humildes e com pouca instrução.

\subsection{Cobertura regional da RBS TV}

O principal e mais longevo programa da RBS TV é o Jornal do Almoço, tendo ido ao ar pela primeira vez no dia 6 de março de 1972. Na época de estreia da atração, ainda não havia o espaço na programação nacional da Rede Globo para telejornais locais no horário do meio dia, tendo sido o Jornal do Almoço um pioneiro neste aspecto $^{7}$. Além do Jornal do Almoço, a emissora ainda apresenta dois outros programas jornalísticos em nível estadual, o "Bom Dia Rio Grande" e o "RBS Notícias", ambos fazendo parte da programação desde o ano de 1983. O Bom Dia Rio Grande vai ao ar das 06h às 08h30min, de segunda à sexta-feira, e é um telejornal que veicula as principais informações para o público que está começando um novo dia. Ele traz informações sobre a previsão do tempo, situação do trânsito, oferta de empregos e notícias gerais sobre diversos temas, com participação de repórteres ao vivo de algumas cidades do interior do estado, mas sem veiculação de blocos regionais de notícias. $\mathrm{O}$ programa RBS Notícias vai ao ar de segunda a sábado, aproximadamente às 19h, fazendo um resumo das notícias do dia, sendo composto de três blocos. Até o ano de 2015, dois blocos de notícias eram estaduais e um bloco de notícias era local de cada região de cobertura, apresentado a partir das cidades do interior com emissoras da RBS TV. A partir do mês de outubro daquele ano, o programa RBS Notícias deixou de apresentar estes blocos regionais, sendo, atualmente, o telejornal transmitido apenas da emissora de Porto Alegre e, embora faça cobertura de notícias do interior, o telejornal não possui um bloco específico regional, sendo o mesmo conteúdo veiculado para todo o estado do Rio Grande do $\mathrm{Sul}^{8}$.

O Jornal do Almoço, ao longo dos seus 48 anos de história, já passou por várias transformações, seja em seu tempo de duração, na alteração de formato ou entre os

\footnotetext{
${ }^{7}$ Disponível em: <http://www.observatoriodaimprensa.com.br/tv-em-questao/pioneirismo-e-ousadia-natv-gaucha/>. Acesso em: 25 abr. 2021.

${ }^{8}$ Disponível em: <https://www.coletiva.net/noticias/2015/10/rbs-tv-extingue-blocos-locais-em-telejornale-anuncia-mudancas/>. Acesso em: 25 abr. 2021.
}

Revista ALTERJOR

Grupo de Estudos Alterjor: Jornalismo Popular e Alternativo (ECA-USP)

Ano 12 - Volume 01 - Edição 25 - Janeiro-Junho de 2022

Av. Professor Lúcio Martins Rodrigues, 443, Cidade Universitária, São Paulo, CEP: 05508-020 
diferentes apresentadores, comentaristas e repórteres que desfilaram pela atração. Ao longo do tempo, o programa ajudou a criar uma referência em relação à apresentação de telejornais no horário do meio dia. Atualmente, o Jornal do Almoço vai ao ar de segunda a sábado das 11 h45min às $12 \mathrm{~h} 55 \mathrm{~min}$. Em relação ao JA, Andres (2008) destaca que o programa é um misto de assuntos relacionados ao humor, esporte e cultura e que tem tido ressignificações no decorrer de seu percurso.

\begin{abstract}
Nota-se que, durante a trajetória do programa, muitas transformações foram se sucedendo, havendo uma mutabilidade de categorias. Essas mudanças estão relacionadas ao processo de desenvolvimento tecnológico, à concorrência que foi se estabelecendo com a criação de outros programas no mesmo horário, ao interesse do público e, às necessidades gerais de mercado (ANDRES, 2008, p.102).
\end{abstract}

A importância do Jornal do Almoço na cultura jornalística e na formação de opinião no público do Rio Grande do Sul pode ser medida, em parte, pela popularidade de seus apresentadores e comentaristas, em que alguns tornaram-se candidatos e foram eleitos para cargos públicos relevantes. Atualmente, dos três senadores que representam o estado do Rio Grande do Sul, um deles é Lasier Martins ${ }^{9}$ (Podemos), que foi apresentador e comentarista do Jornal do Almoço por mais de vinte anos. Na legislatura anterior, o senado federal contava, ainda, com a senadora Ana Amélia Lemos ${ }^{10}$ (PP), também ex-comentarista do Jornal do Almoço. Na região de Pelotas, o único representante na Câmara Federal é o deputado Daniel Trzeciak ${ }^{11}$ (PSDB), que utilizou na campanha o nome "Daniel da TV" e antes exercia a função de repórter no quadro regional do telejornal.

A atração tem como característica a veiculação de espaços regionais, em que jornalistas das cidades com emissoras no interior apresentam notícias e reportagens que fazem parte da sua respectiva área de cobertura. Cabe destacar que nas edições de sábado, já há alguns anos, não estava sendo veiculado o bloco de notícias regionais. Em

\footnotetext{
${ }^{9}$ Eleito em 2014 pelo PDT com 2.145.479 votos

${ }^{10}$ Eleita em 2010 pelo PP com 3.401.241 votos

${ }^{11}$ Eleito em 2018 pelo PSDB com 74.789 votos
}

Revista ALTERJOR

Grupo de Estudos Alterjor: Jornalismo Popular e Alternativo (ECA-USP)

Ano 12 - Volume 01 - Edição 25 - Janeiro-Junho de 2022

Av. Professor Lúcio Martins Rodrigues, 443, Cidade Universitária, São Paulo, CEP: 05508-020 


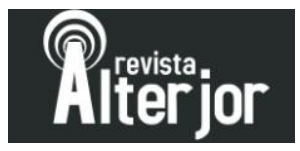

agosto de 2019, a RBS TV promoveu uma campanha chamada "Caravana do JA"12, percorrendo diversas cidades gaúchas e que antecederia uma nova mudança de formato do telejornal. Em relação à caravana, cabe inferir que ela foi focada no reforço de laços do Jornal do Almoço com as cidades do interior. Até então, o grupo de comunicação possuía representação de espaço regional da seguinte forma ${ }^{13}$ : Caxias do Sul (47), Pelotas (22), Santa Maria (36), Passo Fundo (84), Santa Cruz do Sul (64), Uruguaiana (8), Bagé (8), Cruz Alta (23), Santa Rosa (69), Erechim (44), Rio Grande (02), além da capital Porto Alegre (89) ${ }^{14}$.. A partir de então, a RBS TV estruturou uma readequação dos espaços locais no interior do estado e algumas cidades sede foram incorporadas a outras, formando uma nova macrorregião. Assim, Erechim, Cruz Alta e Santa Rosa, incorporaram-se à emissora de Passo Fundo (220), Rio Grande e Bagé passaram a integrar a emissora de Pelotas (32), Uruguaiana passou a fazer parte da emissora Santa Maria (44), Caxias do Sul (47) e Santa Cruz do Sul (64), além de Porto Alegre (89), seguem fazendo a cobertura das mesmas cidades que já integravam a sua região, não integrando nenhuma nova. Desta forma, a RBS TV passou a ser dividida da seguinte maneira com relação à região de cobertura e sua cidade sede: Região Sul e Campanha (Pelotas), Região Centro e Fronteira Oeste (Santa Maria), Região Norte e Noroeste (Passo Fundo), Região Serra (Caxias do Sul), Região dos Vales (Santa Cruz do Sul), além da Capital, Região Metropolitana e Litoral Norte (Porto Alegre).

Com este novo formato de regionalização, o programa Jornal do Almoço passou a apresentar blocos regionais, com a veiculação separada para cada uma de suas novas cinco regiões do interior e de Porto Alegre. Isto importa dizer que, um bloco regional que antes produzia notícias para um determinado número de cidades, agora o acontecimento irá disputar espaço com outros de uma quantidade maior de localidades, fazendo com que muitos fatos percam visibilidade em função do reduzido espaço local.

\footnotetext{
12 Disponível em: <https://redeglobo.globo.com/rs/rbstvrs/noticia/caravana-do-jornal-do-almoco-vaipercorrer-o-interior-do-estado.ghtml>. Acesso: em 25 abr. 2021.

${ }^{13}$ Disponível em <http://www.clicrbs.com.br/pdf/8575330.pdf〉. Acesso em: 21 abr. 2021.

${ }^{14} \mathrm{O}$ número que acompanha cada uma das regiões refere-se ao total de municípios de cobertura.
}

\section{Revista ALTERJOR}

Grupo de Estudos Alterjor: Jornalismo Popular e Alternativo (ECA-USP)

Ano 12 - Volume 01 - Edição 25 - Janeiro-Junho de 2022 Av. Professor Lúcio Martins Rodrigues, 443, Cidade Universitária, São Paulo, CEP: 05508-020 


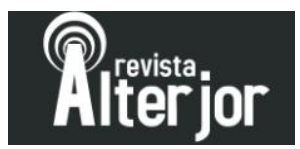

A cobertura da RBS TV Passo Fundo, por exemplo, que antes correspondia a 84 cidades, agora passou a abranger 220 cidades.

Importante destacar que mesmo as cidades do interior que tiveram suas emissoras excluídas para fins de produção de conteúdo, como Rio Grande, Bagé, Uruguaiana, Cruz Alta, Santa Rosa e Erechim, continuaram com os seus setores comerciais em funcionamento e com as respectivas publicidades locais nos seus espaços de intervalo comercial.

Não bastasse a nova política de regionalização que ocasionou a supressão de praças do interior e a diminuição do espaço regional, a pandemia de Covid19 alterou a forma de produção dos conteúdos da maioria dos veículos de comunicação. As normas de distanciamento social, utilizadas como uma das formas de se conter a disseminação do coronavírus, fez com que jornais, rádios e emissoras de televisão adotassem novas práticas para a produção dos seus conteúdos. A partir do mês de março de 2020, muitos profissionais da área do jornalismo passaram a trabalhar a partir das suas residências e as redações e estúdios tiveram uma considerável diminuição da presença de jornalistas. Nas transmissões do Jornal do Almoço, a participação dos quadros regionais, que já havia diminuído, perdeu ainda mais espaço.

A última edição do telejornal no formato com blocos regionais de notícias foi no dia 20 de março de 2020, com um total de 20 minutos destinado a este espaço. A partir da edição de 23 de março de 2020, os blocos de notícias regionais foram substituídos por participações de apresentadores das cidades sedes do interior do estado e com um espaço de tempo bastante reduzido ${ }^{15}$. Cabe ressaltar que a apresentação do Jornal do Almoço transmitido para todo o estado a partir de Porto Alegre, continuou contando no estúdio com, pelo menos, dois apresentadores, o âncora e o destinado ao espaço de previsão do tempo. Também, os repórteres seguiram fazendo matérias das ruas. Isto coloca sob suspeita a justificativa de que a extinção dos blocos regionais tenha sido em função do distanciamento social, pois, da mesma forma, as emissoras do interior poderiam ter um apresentador em estúdio e repórteres produzindo matérias nas ruas.

15 Disponível em: <https://gauchazh.clicrbs.com.br/coronavirus-servico/noticia/2020/03/rbs-tv-anunciamudancas-na-programacao-local-em-funcao-do-avanco-do-coronavirusck80qjtfq00aw01rzctc4n1ix.html>. Acesso em: 25 abr. 2021.

Revista ALTERJOR

Grupo de Estudos Alterjor: Jornalismo Popular e Alternativo (ECA-USP)

Ano 12 - Volume 01 - Edição 25 - Janeiro-Junho de 2022

Av. Professor Lúcio Martins Rodrigues, 443, Cidade Universitária, São Paulo, CEP: 05508-020 


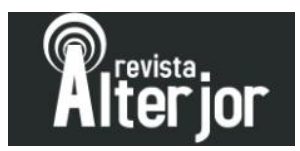

As participações do interior passaram a ser distribuídas ao longo do telejornal, com um tempo médio de cada região de 2 minutos e 44 segundos (de acordo com a análise do período estudado), repercutindo um ou, no máximo, dois fatos da sua respectiva região. Como algumas regiões ficaram territorialmente maiores, muitos acontecimentos das diversas cidades da região acabam deixando de serem vinculados por absoluto limite de espaço e condição de importância, tendo em vista que somente aquele fato mais relevante para a linha editorial do programa é que será o tema pautado no espaço regional.

\title{
2.2 Cobertura regional da TV Cachoeira
}

A TV Cachoeira do Sul LTDA foi fundada em 10 dezembro de 1986, na cidade de Cachoeira do Sul, localizada na região central do Rio Grande do Sul. Inicialmente esteve afiliada à Rede Pampa de Comunicação e retransmitia a programação estadual, assim como a programação nacional da Rede Manchete. Em 1992, a TV Cachoeira afiliou-se à Rede Bandeirantes e anos mais tarde aderiu à TV Shop Tour. Mesmo neste último caso, integrando uma rede de televisão que se caracterizava por anúncios, ofertas e propagandas, a TV Cachoeira manteve a produção de conteúdo jornalístico local, que já fazia parte da programação desde a sua fundação. Em junho de 2011, a TV Cachoeira passa a integrar a TV Novo Tempo, uma rede de televisão nacional que se caracteriza pelo conteúdo religioso ${ }^{16}$. No site da rede social Facebook da TV Cachoeira há a seguinte apresentação: “A TV Cachoeira é uma geradora de televisão, com sede em Cachoeira do Sul RS. Faz parte da Rede Novo Tempo e gera seu sinal para mais de 200 cidades" (TV CACHOEIRA/FACEBOOK, WEB, S/P). O site FindGlocal também traz informações sobre a TV Cachoeira:

\begin{abstract}
A TV Cachoeira é uma emissora de televisão brasileira sediada no município de Cachoeira do Sul, no estado do Rio Grande do Sul. Opera no canal 11 VHF e no canal 46 UHF (11.1 digital). É a Rede Novo Tempo em canal aberto, e retransmite seu sinal para cerca de 200 municípios no Brasil. Sua sede fica bem no centro de Cachoeira do Sul, na esquina entre as ruas Sete de Setembro e Major Ouriques. O parque de transmissões fica na Zona Norte, no bairro Otaviano (FINDGLOCAL, web, s/p).
\end{abstract}

\footnotetext{
${ }^{16}$ Histórico da TV Cachoeira. Disponível em: https://pt-br.facebook.com/notes/1933239083373330/ Acesso em: 15 dez. 2020.
}

\section{Revista ALTERJOR}

Grupo de Estudos Alterjor: Jornalismo Popular e Alternativo (ECA-USP)

Ano 12 - Volume 01 - Edição 25 - Janeiro-Junho de 2022 
O Jornal NT Sul foi ao ar pela primeira vez no ano de $2015^{17}$ e se mantém no ar até os dias de hoje. O horário do telejornal é das $12 \mathrm{~h}$ às $13 \mathrm{~h}$, de segunda à sexta-feira (praticamente o mesmo horário do Jornal do Almoço), com edições especiais aos finais de semana, às $21 \mathrm{~h}$ aos sábados e às $11 \mathrm{~h}$ aos domingos.

De acordo com a estimativa do IBGE (2020), a cidade de Cachoeira do Sul tem uma população de 81.869 (oitenta e um mil, oitocentos e sessenta e nove) habitantes. O sinal local da emissora se estende para cidades como Agudo, Encruzilhada do Sul, Formigueiro, Novo Cabrais, Paraíso do Sul, Restinga Seca, São Sepé, Rio Pardo, Pantano Grande e outros municípios da região.

\section{Perspectivas metodológicas}

Diferentemente de outras emissoras em nível estadual, que transmitem seus programas jornalísticos para todo o estado com o mesmo conteúdo, a RBS TV, através do programa Jornal do Almoço, até o início da pandemia de Covid19 ainda possuía produção jornalística a partir de cidades do interior do estado e com notícias específicas para cada uma das regiões de cobertura, mesmo que viesse em um processo de diminuição de conteúdo regionalizado em decorrência de um novo formato de estruturação. Esta atuação do telejornal da RBS TV será analisada comparativamente com o Jornal NT Sul, da TV Cachoeira, que produz um telejornal com notícias voltadas especificamente para o público da sua região. O objetivo da pesquisa é problematizar a importância do jornalismo regional para a população do interior gaúcho, traçando um perfil de diferenciação entre um telejornal que "fala de" uma determinada região e um outro que "fala para" a região onde está inserido. Através da observação das notícias veiculadas nos dois telejornais, serão analisados os noticiários das duas emissoras durante o período de uma semana, entre os dias 07 a 11 de dezembro de 2020, totalizando cinco edições de cada programa. Vamos tomar como perspectiva metodológica o método observacional (GIL, 2008). Sobre a observação cabe enfocar:

\footnotetext{
${ }^{17}$ Disponível em: https://tvcachoeira.novotempo.com/programa/jntsul/ Acesso em 09 abr. 2021.

Revista ALTERJOR

Grupo de Estudos Alterjor: Jornalismo Popular e Alternativo (ECA-USP)

Ano 12 - Volume 01 - Edição 25 - Janeiro-Junho de 2022 Av. Professor Lúcio Martins Rodrigues, 443, Cidade Universitária, São Paulo, CEP: 05508-020
} 
A observação constitui elemento fundamental para a pesquisa. Desde a formulação do problema, passando pela construção de hipóteses, coleta, análise e interpretação dos dados, a observação desempenha papel imprescindível no processo de pesquisa. É, todavia, na fase de coleta de dados que o seu papel se torna mais evidente. A observação é sempre utilizada nessa etapa, conjugadas a outras técnicas ou utilizada de forma exclusiva. Por ser utilizada, exclusivamente, para a obtenção de dados em muitas pesquisas, e por estar presente também em outros momentos da pesquisa, a observação chega mesmo a ser considerada como método de investigação. (GIL, 2008, p. 100)

Através da observação de cinco edições dos dois telejornais durante o período, foram destacados os quadros de notícias com apresentação ou repercussão de fatos do interior do estado no Jornal do Almoço e as notícias que tratavam de temas relacionados ou com enfoque na cidade de Cachoeira do Sul, no Jornal NT Sul.

\section{Análise das edições dos telejornais}

Foram analisados cinco telejornais de cada uma das duas emissoras, de segunda à sexta-feira, sendo o período escolhido aleatoriamente, compreendido entre os dias 07 a 11 de dezembro de 2020.

Nestes programas, a duração total do Jornal do Almoço teve um tempo mínimo 1 hora e 1 minuto na edição de sexta-feira e um máximo de 1 hora e 4 minutos na edição de segunda-feira. A soma dos tempos da participação de notícias das cinco regiões de cobertura (Serra, Norte, Centro/Oeste, Sul/Campanha, Vales) ficou em um intervalo de 9 minutos e 51 segundos na edição de segunda-feira e 17 minutos e 43 segundos na edição de quinta-feira. Também, na edição de quinta-feira, foi observado o maior tempo de duração do quadro de notícias regionais, que foi referente a região Serra, com duração de 5 minutos e 21 segundos. No entanto, a maior reportagem desta edição foi uma matéria sobre pessoas oriundas da região que moram na Europa, falando a respeito das suas impressões sobre o começo da vacinação no Reino Unido. Esta matéria durou 3 minutos e 30 segundos e não se pode afirmar que, necessariamente, seja um assunto que interesse ou interfira diretamente na vida das pessoas que moram na região da Serra, pois trata de um tema com repercussão mundial e, neste caso, a relação se deu porque as pessoas eram originárias da região. Resumidamente, nas cinco edições

\section{Revista ALTERJOR}

Grupo de Estudos Alterjor: Jornalismo Popular e Alternativo (ECA-USP)

Ano 12 - Volume 01 - Edição 25 - Janeiro-Junho de 2022 


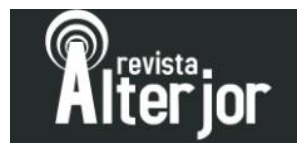

analisadas do Jornal do Almoço, os tempos dos quadros regionais de notícias em relação à duração total do telejornal pode ser visualizado a seguir (quadro 1):

Quadro 1: Duração dos quadros regionais no total do Jornal do Almoço

\begin{tabular}{|l|l|l|}
\hline Jornal do Almoço & Quadros regionais & Participação regional \\
\hline 5 h,12 min, 30 seg. & $1 \mathrm{~h}, 8 \mathrm{~min}, 25 \mathrm{seg}$. & $21,89 \%$ \\
\hline
\end{tabular}

Fonte: o autor

Segundo dados do Instituto Brasileiro de Geografia e Estatística (IBGE), o estado do Rio Grande do Sul possuía, no ano de 2020, uma população estimada de 11.422.973 (onze milhões, quatrocentos e vinte e dois mil, novecentos e setenta e três) habitantes, sendo a capital Porto Alegre a cidade mais populosa, com 1.488.252 (um milhão, quatrocentos e oitenta e oito mil, duzentos e cinquenta e dois) habitantes, enquanto a soma da população das outras onze cidades em que a RBS possui emissoras é de 2.180.643 (dois milhões, cento e oitenta mil, seiscentos e quarenta e três) habitantes. Se fosse considerado apenas as cidades sedes das emissoras na relação com Porto Alegre, o interior representaria uma população 46,5\% maior do que a capital, sem levar em conta, ainda, todas as outras cidades que fazem parte das respectivas regiões.

Cabe ressaltar que ao longo desta semana de avaliação, houve outras notícias veiculadas pelo Jornal do Almoço fora dos quadros regionais que se referiam a fatos ocorridos no interior do estado, tais como "Papai Noel em Canela", "Ações solidárias de Natal" em Santa Maria e Passo Fundo, "Ganso que passeia pelas ruas com o seu dono", em Bento Gonçalves. Porém, estas notícias extrapolam o critério de proximidade, pois invocam o inusitado, no caso do Ganso, ou a temática do Natal que é o momento que estava sendo vivenciado. Também se observou duas matérias produzidas no interior, mas que foram veiculadas em nível estadual, como o reajuste no preço do gás, que foi produzida pela RBS TV Pelotas, e o atraso em obras de creches públicas, produzida pela RBS TV Erechim. Nestas reportagens, o início da matéria era na cidade originária da produção e depois havia a contextualização com outras cidades do estado, tratando-se, portanto, de uma reportagem em nível estadual.

\section{Revista ALTERJOR}

Grupo de Estudos Alterjor: Jornalismo Popular e Alternativo (ECA-USP)

Ano 12 - Volume 01 - Edição 25 - Janeiro-Junho de 2022 Av. Professor Lúcio Martins Rodrigues, 443, Cidade Universitária, São Paulo, CEP: 05508-020 


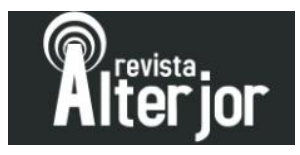

No Jornal NT Sul, o tempo mínimo de duração das edições foi de 52 minutos e 49 segundos, no dia 11 de dezembro, e o máximo de 57 minutos e 1 segundo, no dia 09 de dezembro. A característica deste telejornal é a veiculação de notícias da cidade de Cachoeira do Sul, com algumas matérias de nível estadual ou nacional veiculadas, mas, mesmo assim, quase sempre é dado um enfoque local ao tema. Em uma reportagem sobre o mapa estadual de bandeiras do distanciamento controlado do coronavírus, foi destacada a cor vermelha da região a qual pertence a cidade de Cachoeira do Sul e houve o detalhamento de todas as atividades que seriam afetadas e os respectivos horários de restrição. Outro exemplo, foi uma matéria produzida no Rio de Janeiro sobre cultivo de uma determinada espécie de arroz, o que se relaciona com a cidade e a região, pois esta é uma das maiores produtoras do grão e a sua principal atividade econômica.

No caso do Jornal NT Sul, a análise não se aprofundou na especificação numérica dos tempos de duração das matérias, pois as notícias veiculadas em nível estadual, nacional ou mundial em que não são dados enfoques locais são muito esporádicas e tomam um espaço curto de tempo. Na observação de uma semana de segunda à sexta-feira, foram verificadas algumas poucas e rápidas matérias, como sobre uma votação no Supremo Tribunal Federal (STF), a isenção do governo federal do imposto sobre armas, a publicação de regras sobre a vacina de Covid19 pela Anvisa, inauguração da ponte do Guaíba, queda nos dados de criminalidade no Rio Grande do Sul, entre outras. No entanto, a maioria absoluta das notícias dizem respeito à cidade de Cachoeira do Sul.

O telejornal, no período em análise, sempre abriu a edição com uma primeira notícia atualizando os dados de coronavírus na cidade (novos infectados, recuperados, óbitos), além da situação da ocupação dos hospitais da região. Outras matérias veiculadas de interesse local ao longo da semana foram: abastecimento de água na cidade; inscrições abertas para escola técnica; ideias de presentes da casa do artesão; obras no centro de proteção animal; acidente de trânsito no centro da cidade; novos cursos superiores disponíveis na cidade; votação na câmara de vereadores sobre fundo de pensão dos servidores municipais; estoque de medicamentos à disposição na 


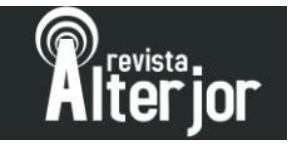

farmácia municipal; elaboração do caderno pedagógico pela Secretaria Municipal de Educação; pagamento pela prefeitura municipal do $13^{\circ}$ salário dos servidores; calendário de pagamento do IPTU; falta de tratamento de esgoto na cidade; atendimento da UPA especializada em Covid19; tempo de espera pelos resultados de exames da Covid19; obras da Companhia Rio-Grandense de Saneamento (Corsan) para evitar falta de água na cidade; retomada do atendimento do cartório eleitoral; substituição polêmica de diretora de escola municipal; transporte público municipal em desacordo com as regras de distanciamento; entre outras. Além das reportagens, foram realizadas várias entrevistas com longo tempo de duração, como a de vereadores eleitos para o próximo mandato; do novo presidente do Instituto Rio-Grandense do Arroz (IRGA); do novo presidente da Associação do Ministério Público do RS, que é natural de Cachoeira do Sul; com o diretor do campus de Cachoeira do Sul da Universidade Luterana do Brasil (Ulbra).

Algumas edições do telejornal apresentam também um quadro com dicas de profissionais locais sobre educação, alimentação e vida animal. Estes quadros proporcionam que, além das dicas em diferentes seguimentos, o telejornal valorize os profissionais da cidade através da visibilidade oferecida, o que aproxima o telespectador e promove o envolvimento da sociedade em diferentes temas e o desenvolvimento local.

Além do enfoque regional, outra diferença constatada entre o Jornal NT Sul e o Jornal do Almoço é com relação a participação do público nos canais de interatividade (Whatsapp, Facebook, etc.). Nos dois telejornais o telespectador é convidado a participar, no entanto, o conteúdo das mensagens é diferenciado. Como exemplo, citamos mensagens de telespectadores dos dois telejornais das edições do dia 07 de dezembro. No Jornal NT SUL, foram várias mensagens ao longo do programa e entre elas destacamos três, todas de telespectadores de Cachoeira do Sul: "Sempre ligada no melhor jornal. Gostaria de parabenizar meu filho pelo seu aniversário hoje. Feliz aniversário Bernardo, te amamos muito". (foto da criança); "Perigo no bairro Marina. Escada continua com degraus quebrados e sem corrimão. Sem contar o mato que toma conta do local" (foto das condições da rua); "No postinho do Ponche Verde está muito ruim o atendimento. Eu pedi um RX do meu joelho que não doía muito por conta de um 


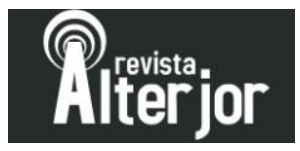

tombo. Disseram que se continuasse doendo até 5 dias era para eu voltar lá e fazer o RX” (sem foto). No Jornal do Almoço, foram apresentadas quatro mensagens ao final do programa: "Que o Natal venha cheio de luz, esperança e energia boa”. (foto de uma árvore de Natal - telespectador de Bento Gonçalves); “Aqui em casa já estamos esperando a visita do Papai Noel. Sou de Itaqui. Assisto sempre o Jornal do Almoço". (foto de uma árvore de Natal - telespectador de Itaqui); "Bom dia. Luana de Nova Petrópolis, tia do Bernardo que mora em Caxias do Sul, nosso lindo". (foto da criança telespectador de Nova Petrópolis); "Depois de uma boa chuva tudo muda". (foto de uma parreira de uvas - telespectador de Bento Gonçalves)

Podemos constatar que enquanto no Jornal do Almoço os temas enviados pelo público são mais leves e descontraídos, o Jornal NT Sul também destaca este tipo de participação, mas vai além, ao reproduzir mensagens com tom mais crítico, como reclamações sobre serviços públicos na cidade, servindo como um canal de denúncias sobre determinados fatos, o que acaba criando uma retroalimentação para o jornalismo, pois, desta forma, o telespectador pode influenciar na pauta do programa, ao invés de apenas utilizar o telejornal como uma reprodução das mídias sociais.

\section{Considerações finais}

O acesso à informação é um direito fundamental e o jornalismo serve com um mediador entre os acontecimentos e a divulgação dos fatos à população, inclusive, para aquele cidadão que more no rincão mais distante dos grandes centros urbanos. Nos últimos anos, canais abertos de televisão fecharam espaços regionais ou reduziram drasticamente a produção de conteúdo, como é o caso da RBS TV, que ainda é a emissora de televisão em canal aberto com abrangência em todo o estado do Rio Grande do Sul que atende em parte esta demanda. No entanto, ela tem, aos poucos, se distanciado de uma das suas premissas, que era a regionalização e a cobertura de fatos regionais do interior do estado.

Em tempos de pandemia e de tantas informações duvidosas que cada vez mais circulam na internet, o jornalismo profissional ganha ainda mais importância, 


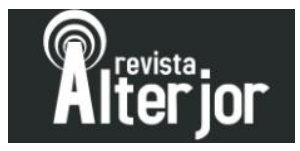

especialmente a televisão, que possui a maior confiança entre as mídias jornalísticas ${ }^{18}$. Com todos os problemas diretamente e indiretamente causados pela crise sanitária envolvendo a Covid19, em que a população mais necessita de informação de utilidade pública sobre os serviços de saúde, número de infectados, localização de surtos, situação dos hospitais, cronogramas locais de vacinação, condições de funcionamento de atividades comerciais, oportunidades ou alternativas de trabalho locais, enfim, tantos temas que estão intimamente ligados à vida da população, a informação com credibilidade, ética e responsabilidade é fundamental na vida das pessoas.

O ano de 2020 também se destacou sob o aspecto político, pois ocorreram as eleições municipais para prefeitos e vereadores e não há dúvida de que este processo afeta diretamente a vida das pessoas que habitam as cidades. Com a diminuição de espaço de tempo regional na RBS TV, as propostas de candidatos e o debate político ficou prejudicado, pois a informação jornalística isenta é de fundamental importância para a escolha dos candidatos pelo eleitor e para o futuro das comunidades.

O distanciamento percebido do jornalismo televisivo nas comunidades do interior é extremamente prejudicial ao acesso à informação, fator crucial para a sociedade exercer a sua cidadania e a democracia. Uma emissora de televisão é uma concessão pública fornecida pelo governo federal e deve ter como uma de suas finalidades o oferecimento de informação de qualidade e prestação de serviço às comunidades das quais fazem parte.

No entanto, a realidade que tem se mostrado é que a manutenção de emissoras de televisão em cidades do interior do Rio Grande do Sul parece possuir um foco basicamente mercadológico, em que as relações comerciais são mais determinantes do que produzir um conteúdo regional voltado às suas populações. Porém, existem experiências que vão na contramão desta perspectiva, como é o caso da TV Cachoeira e do seu Jornal NT Sul, que serve como alento e exemplo de como é possível a produção de conteúdo jornalístico de qualidade e com informação específica voltada ao

\footnotetext{
${ }^{18}$ Pesquisa da Kantar Ibope Media divulgada pela Acaert (2020) aponta crescimento na audiência e busca de informação na televisão durante a pandemia.
}

\section{Revista ALTERJOR}

Grupo de Estudos Alterjor: Jornalismo Popular e Alternativo (ECA-USP)

Ano 12 - Volume 01 - Edição 25 - Janeiro-Junho de 2022 


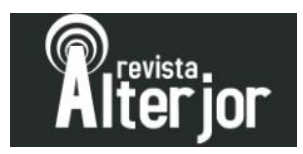

telespectador regional, fazendo com que uma emissora de televisão cumpra mais adequadamente a sua função social.

\section{Referências}

ANDRES, Márcia Turchiello. A trajetória do Jornal do Almoço: ciclos e fragmentos históricos da comunicação capitalista. São Leopoldo, 2008. Disponível em: <http://www.repositorio.jesuita.org.br/bitstream/handle/UNISINOS/2623/trajetoria\%20do \%20jornal.pdf?sequence=1\&isAllowed=y >. Acesso em 20 de julho de 2021 .

ASSIS, Claudia Maria Arantas; RANGEL, Priscila de Paula. A IMPORTÂNCIA DO JORNALISMO REGIONAL: TENDO COMO OBJETODE ESTUDO O JORNAL CORREIO CENTRO -OESTE. In: Intercom Sudeste, 2006, Ribeirão Preto. Anais... Ribeirão Preto: Intercom Sudeste, 2006.

BOURDIEU, Pierre. Sobre a televisão. Rio de Janeiro: Zahar, 1997.

FERNANDES, Carolina. Telejornalismo regional: uma análise dos critérios de noticiabilidade utilizados no Jornal 53 diante da contribuição organizacional e social. 2020. Disponível em: http://www.bocc.ubi.pt/pag/fernandes-carolina-telejornalismo-regional.pdf. Acesso em 29 de julho de 2021.

FERRAZ, Arnaldo. TV Bauru - TV TEM - Os caminhos da Regionalização. 2005.

Dissertação (Mestrado em Comunicação). Programa de Pós Graduação em Comunicação Faculdade de Arquitetura, Artes e Comunicação da Unesp / Campus de Bauru/SP. Disponível em:

<http://www.dominiopublico.gov.br/pesquisa/DetalheObraForm.do?select_action=\&co_obra=9 3121>. Acesso em 25 abr. 2021.

FINDGLOCAL. TV Cachoeira. Disponível em: http://www.findglocal.com/BR/Cachoeira-doSul/817955681568348/TV-Cachoeira. Acesso em 21 de julho de 2021.

FINGER, Cristiane. Os 50 Anos de História da Televisão no Rio Grande do Sul. 2009.

Disponível em: http://www.rua.ufscar.br/os-50-anos-de-historia-da-televisao-no-rio-grande-dosul/. Acesso em: 29 de julho de 2021.

GIL, Antonio Carlos. Métodos e técnicas de pesquisa social. 6ª ed. São Paulo: Atlas, 2008.

IBGE. Estimativa da população. Cidades RS. Disponível em: https://www.ibge.gov.br/cidadese-estados/rs/ estimativa população cidades Rio Grande do Sul Acesso em: 17 dez. 2020.

JORNAL DO ALMOÇO. Programas. Disponível em https://globoplay.globo.com/jornal-doalmoco/t/bPzKqk9zLH/ Acesso em: 15 dez. 2020.

NT SUL. Programas. Disponível em: https://www.novotempo.com/programa/ntsul/ Acesso em: 15 dez. 2020.

\footnotetext{
Revista ALTERJOR

Grupo de Estudos Alterjor: Jornalismo Popular e Alternativo (ECA-USP)

Ano 12 - Volume 01 - Edição 25 - Janeiro-Junho de 2022

Av. Professor Lúcio Martins Rodrigues, 443, Cidade Universitária, São Paulo, CEP: 05508-020
} 
PINNA, Aline Fonseca. Telejornalismo regional de Juiz de Fora nas telas e nas redes: uma análise das novas funções e competências. Dissertação (mestrado). Universidade Federal de Juiz de Fora, Faculdade de Comunicação Social. Programa de Pós-graduação em Comunicação, 2020 .

PUHL, Paula. TELEJORNALISMO REGIONAL E TELEVISÃO UNIVERSITÁRIA: UNIDOS PELO VIVER JUNTO NA CONSTRUÇÃO DA NOTÍCIA. Ânimus, Santa Maria, Vi13, n.26, 2014.

REIS, Thays Assunção. Jornalismo Regional: uma leitura a partir dos critérios de noticiabilidade do jornal o progresso. Estudos em Jornalismo e Mídia, [S.L.], v. 15, n. 1, p. 62-72, 4 set. 2018. Universidade Federal de Santa Catarina (UFSC). Disponível em: <http://dx.doi.org/10.5007/1984-6924.2018v15n1p62>. Acesso em 21: abr. 2021.

RIBEIRO, Juliana Colussi. Jornalismo regional e construção da cidadania: o caso da Folha da Região de Araçatuba. 2005. 187 f. Dissertação (mestrado) - Universidade Estadual Paulista, Faculdade de Arquitetura, Artes e Comunicação de Bauru, 2005. Disponível em: Disponível em: <http://hdl.handle.net/11449/89429>. Acesso em: 22 abr. 2021.

TRAQUINA, Nelson. Teorias do Jornalismo: A tribo jornalística - uma comunidade interpretativa transnacional. 2.ed. Florianópolis: Insular, 2008.

TV CACHOEIRA/ FACEBOOK. TV Cachoeira. Disponível em: https://www.facebook.com/tvcachoeira/. Acesso em 20 de julho de 2021.

WOLF, Mauro. Teorias da comunicação de massa. São Paulo: Martins Fontes, 2003. 